\title{
Routine radionuclide techniques in evaluation of patients with suspected coronary heart disease
}

\author{
ERIK THAULOW, KJELL ROOTWELT, JAN ERIKSSEN, SIGURD NITTER-HAUGE \\ From the Laboratory of Cardiology, Medical Department B, and Section of Nuclear Medicine, Department of \\ Clinical Chemistry, Rikshospitalet, The National Hospital, University of Oslo, Oslo, Norway
}

SUMMARY Myocardial scintigraphy with thallium-201 and electrocardiogram-gated left ventriculography with technetium-99m labelled red blood cells were applied in four groups of subjects: 25 with no signs or symptoms of cardiovascular disease (group 1), 28 with a "false" positive exercise electrocardiogram (group 2), 14 with angina pectoris and normal coronary angiograms (group 3), and 43 with angina pectoris and fixed coronary artery stenoses (group 4). In groups 1 and 4 the radionuclide findings were in accordance with clinical and invasive measurements. In groups 2 and 3 the most important finding was the lack of increase in left ventricular ejection fraction during exercise in about half of these subjects (even a decrease in $25 \%$ ), indicating subnormal myocardial reserve. The additional finding of pathological myocardial biopsies in four of these patients suggests that asymptomatic ST depression in patients with normal coronary angiograms may in some cases represent an early, preclinical sign of cardiomyopathy.

Radionuclide techniques added to conventional evaluation such as exercise testing and angiographic studies have provided valuable additional information concerning myocardial function in the study of patients with overt coronary heart disease..$^{1-3}$

Among the most widely used radionuclide tests are (1) the study of myocardial perfusion during exercise and in the redistribution phase using thallium-201 $\left({ }^{201} \mathrm{Tl}\right)$, and (2) the study of left ventricular function at rest and during exercise using technetium-99m

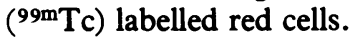

An increasing number of patients with mild or atypical angina pectoris or with ST depression without symptoms found during screening exercise electrocardiographic testing are currently being referred to our hospital for further evaluation. A question of major interest is whether the above mentioned radionuclide techniques can provide more accurate diagnostic data in such patients, ${ }^{45}$ and also provide information unobtainable from conventional invasive techniques. With these questions in mind we have applied the two tests mentioned above in patients with angina or a positive exercise electrocardiogram response discovered prospectively, but in whom coronary angiography disclosed normal findings.

Accepted for publication 18 May 1982

\section{Subjects and methods}

Included in the study were 110 subjects, who all gave informed consent. None had valvular or congenital heart disease. They are subdivided into four groups (see below). Groups 1 and 2 are derived from a prospective cardiovascular survey group of 2014 apparently healthy middle aged men. All 115 men fulfilling predetermined criteria of having suspected coronary heart disease were offered coronary angiography to confirm or exclude this suspicion. The details about that survey (including angiographic findings) have been published elsewhere. ${ }^{6}$ The latter two groups ( 3 and 4) include patients referred to our department for evaluation of incapacitating angina pectoris.

\section{GROUP 1:25 NORMAL SUBJECTS}

Group 1 was selected randomly from the cardiovascular survey among men fulfilling the following criteria on two examinations performed seven years apart: no symptoms or signs of coronary heart disease or other heart disease, normal blood pressure, normal findings on $x$-ray film of the heart and lungs, normal resting electrocardiogram, and a negative response to a near maximal exercise test (heart rate of at least $90 \%$ of predicted maximal heart rate) without abnormalities in the electrocardiogram. ${ }^{6}$ The mean age was 54.6 years (SD 5.5 years). 
GROUP 2:28 "FALSE” POSITIVE EXERCISE ELECTROCARDIOGRAM

These 28 men had a "false" positive exercise electrocardiogram during the primary study (described above); that is significant ST depression, but normal coronary arteries on the angiogram. ${ }^{6}$ This group originally included 36 men. At follow-up after seven years, two had died suddenly, three had congestive heart failure, two had diseases of the locomotor system which made exercise testing impossible, and one had moved to another area. The remaining 28 men from this group were re-examined and all had similar ST depression on their exercise electrocardiogram to that recorded seven years earlier. A second angiographic study-during which myocardial biopsies were obtained-was performed in four of these 28 men in an attempt to clarify further their disease. ${ }^{7-9}$ The mean age of this group was 56.1 years (SD 5.1 years).

\section{GROUP 3: 14 PATIENTS WITH ANGINA PECTORIS AND NOR MAL ANGIOGRAMS}

This group represents a consecutive series of 14 patients (six women and eight men) referred to hospital because of incapacitating angina and whose coronary angiograms were normal. Three had significant ST depression on their exercise electrocardiograms and 11 had a normal exercise electrocardiogram. Mean age was 46.9 years (SD 6.6 years).

GROUP 4: 43 PATIENTS WITH ANGINA PECTORIS AND FIXED CORONARY ARTERY STENOSES These patients represent a consecutive series of 43 patients (four women and 39 men) with severe angina and pathological coronary angiograms. All had at least one stenosis $\geqq 70 \%$ of the vessel area in one of the major epicardial arteries. Thirty-two had had a myocardial infarction. Eighteen had significant ST depression on the exercise electrocardiogram, 11 had stress tests with normal electrocardiographic findings, and in 14 we could draw no conclusions on exercise testing because of the effects of drug treatment. Mean age was $55 \cdot 1$ years (SD 7.1 years).

\section{Methods}

\section{EXERCISE TESTING}

This was started at 50 watts in groups 3 and 4 and at 100 watts in groups 1 and 2 , and the load was increased stepwise by 50 watts every six minutes. Endpoints of the exercise tests were: angina, ST depression $\geqq 3 \mathrm{~mm}$, severe dyspnoea, general fatigue/exhaustion, arrhythmias, or any combination of these factors. Chest-head leads $\mathrm{CH} 1-7$ were used during exercise and 12 lead electrocardiograms before, and for five minutes after exercise. A positive exercise electrocardiogram was defined as one with ST depression $\geqq 1.5 \mathrm{~mm} 0.08 \mathrm{~s}$ from the J point in $\mathrm{CH} \stackrel{\vec{c}}{\mathrm{c}}$ leads $2-7$, or $1.0 \mathrm{~mm}$ in leads I, II, aVF, aVL, or V2-7, $\overrightarrow{\overline{\vec{*}}}$ irrespective of whether the ST segment was upwardor downward-sloping or horizontal. 6

Coronary angiography was performed as described by Judkins. ${ }^{10}$

\section{RADIONUCLIDE PROCEDURES}

An identical exercise test procedure was used for the ${ }^{201} \mathrm{Tl}$ perfusion imaging and radionuclide ventriculog- . raphy, and was similar to the above mentioned procedure except for the fact that during the radionuclide studies the patients were exercised supine with the trunk immobilised. Cardiac scintigrams were obtained with a GE scintilation camera (Maxicamera $400 \mathrm{~T}$ ) with hardware 2:1 zoom. The camera was interfaced to an Intertechnique cine $\mathbf{3 3 0}$ data system.

\section{PERFUSION SCINTIGRAPHY}

$60 \mathrm{mli}{ }^{201} \mathrm{Tl}$ was injected in an antecubital vein when $\vec{\oplus}$ peak load was reached, and 90 seconds before termi- $\mathbb{D}$ nation of the exercise. Immediately after exercise and $\stackrel{\vec{\Phi}}{\mathbb{D}}$ five hours later images were obtained in three views $\frac{7}{8}$ by collecting 200000 counts per image. Areas showing diminished uptake in the immediate post-exercise $\vec{C}$ period were scrutinised for differences in the pattern five hours later. Reversible ischaemia was said to be present in patients in whom perfusion defects were observed immediately after exercise and in whom the uptake was normal five hours later. Myocardial scar- $\bar{\partial}$ ring was thought to be present when perfusion defects were observed immediately after exercise, persisting $\stackrel{\varnothing}{\circ}$ unaltered five hours later.

\section{RADIONUCLIDE VENTRICULOGRAPHY}

This was performed as multiple gated acquisition at equilibrium after in vivo labelling of erythrocytes with $900 \mathrm{mli}$ of ${ }^{99 \mathrm{~m}} \mathrm{Tc}$ pertechnetate. The detector was located in the $40^{\circ}$ left anterior projection with $15^{\circ}$ caudal tilt. In list mode 1500000 counts were stored together with the electrocardiogram. Composite cardiac cycles ( 16 frames) were computer generated. Left $\delta$ ventricular end-diastolic and end-systolic contours were operator outlined. Left ventricular ejection frac- 은 tion was calculated as end-diastolic counts - end sys- $D$ tolic counts divided by end-diastolic count after back- 을. ground subtraction. An increase in left ventricular $\vec{N}$ ejection fraction from resting to exercise values of less than 5\% was considered as pathological. ${ }^{11} 12$ Regional $\mathrm{N}$ wall motion abnormalities were assessed by cinematic $N$ display of the composite cardiac cycles, and by con- $\underset{<}{\sigma}$ struction of stroke volume images, paradox images, 0 and regional ejection fraction images.

\section{Results (see Fig.)}

GROUP 1: NORMAL SUBJECTS

All 25 subjects had normal perfusion according to the $\frac{\rho}{\Phi}$ 
${ }^{201} \mathrm{Tl}$ study. Left ventricular ejection fraction increased from $68.4 \%$ (SD 6.5) at rest to $76.0 \%$ (SD $7 \cdot 1)$ during exercise $(p<0.01)$. Only one man $(62$ years old) increased his left ventricular ejection fraction by less than $5 \%$ during exercise $(=4 \%)$. The remaining 24 men increased theirs by 6 to $19 \%$. There was no association between age and increase in left ventricular ejection fraction during exercise (data not shown). Abnormal wall motion could neither be detected at rest nor during exercise in any of the normal subjects.

\section{GROUP 2: "FALSE” POSITIVE EXERCISE}

ELECTROCARDIOGRAM

The 28 men with a "false" positive exercise electrocardiogram all showed normal myocardial perfusion at rest and during exercise. Left ventricular ejection fraction was $67.0 \%($ SD 8.1$)$ at rest and showed a moderate increase to $70.3 \%$ (SD 11.3 ) during exercise $(p<0.05)$. In 15 of the 28 men, however, left ventricular ejection fraction increased by less than $5 \%$,

\section{MYOCARDIAL PERFUSION}
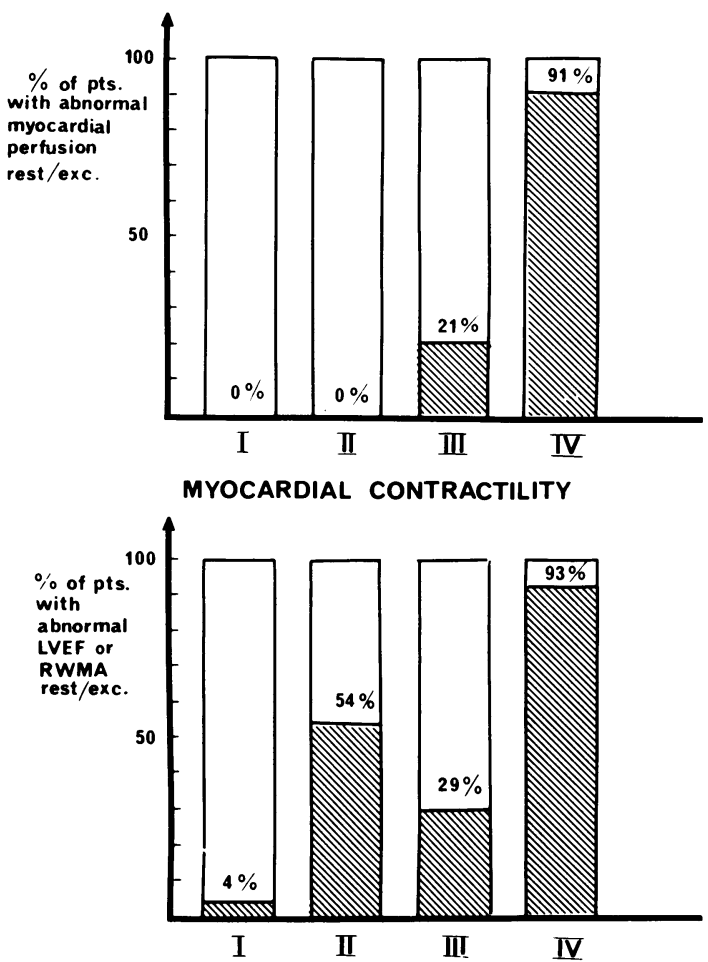

Fig. Myocardial perfusion and contractility pattern in four groups of patients studied with ${ }^{201} \mathrm{Tl}$ scintigraphy and $99 \mathrm{~m} T \mathrm{C}$ ventriculography. See text for details of groups. LVEF, left ventricular ejection fraction; RWMA, regional wall motion abnormalities. and in seven of these 15 the left ventricular ejection fraction actually decreased during exercise. No abnormal wall motion could be detected.

The myocardial biopsies showed nonspecific changes with atrophy and hypertrophy of the muscle fibres in three patients and oedema and interstitial fibrosis in one patient. All had end-diastolic pressures greater than $12 \mathrm{mmHg}$ at rest and three greater than $20 \mathrm{mmHg}$ after angiography. Left ventricular ejection fraction was unaltered during exercise in all four patients.

GROUP 3: ANGINA PECTORIS, NORMAL CORONARY ANGIOGRAMS

In 11 of the 14 patients normal myocardial perfusion was found both at rest and during exercise. Two presented regional perfusion defects during exercise with normal perfusion five hours later, whereas one showed regional perfusion defect during exercise as well as five hours later. The resting left ventricular ejection fraction, 64.0\% (SD 7.9), increased significantly during exercise to $71.2 \%$ (SD 11.6; $\mathrm{p}<0.01)$. In four patients the increase was less than $5 \%$ (including two with a decrease in left ventricular ejection fraction during exercise). Regional wall motion abnormalities were not seen in this group. Perfusion defects and/or subnormal left ventricular ejection fraction response during exercise were found in five in this group.

\section{GROUP 4: ANGINA PECTORIS WITH FIXED}

CORONARY ARTERY STENOSES

Thirty-nine of the 43 patients had pathological ${ }^{201} \mathrm{Tl}$ images, either as myocardial scarring (32) or reversible ischaemia (26), or both. Of the 32 with a previous myocardial infarction, 31 were shown to have myocardial scarring on ${ }^{201} \mathrm{Tl}$ scintigraphy. The left ventricular ejection fraction decreased from $46.3 \%$ (SD 15.9 ) to $41.8 \%$ (SD 15.3) during exercise $(p<0.01)$. In 38 of 43 patients the left ventricular ejection fraction either decreased or increased by less than $5 \%$, that is only five in this group showed the normal increase in left ventricular ejection fraction during exercise. Regional wall motion abnormalities were found in 17. All 43 from this group had at least one pathological radionuclide test finding.

\section{Discussion}

The diagnosis of coronary heart disease is made in most patients admitted to hospital from clinical symptoms and resting and exercise electrocardiographic findings, and can be verified by coronary angiography. Under such circumstances radionuclide techniques, as shown by ${ }^{201} \mathrm{Tl}$ scintigraphy and ${ }^{99 \mathrm{~m}} \mathrm{Tc}$ ventriculography, indicate disease which accords with the 
angiographic and clinical findings. The inclusion of such patients in the present report as well as the inclusion of men thought to be normal (those in group 1) was done in order to document the reliability of the radionuclide techniques in our hands. Our findings agree closely with those of other investigators. ${ }^{1-3}$ Thus, the radionuclide studies disclosed disease in all 43 patients with angiographically documented coronary heart disease. The diagnostic considerations, however, proved to be more ambiguous among the patients with normal angiograms from groups 2 and 3 . The knowledge of the presence or absence of significant coronary artery disease in such patients has prognostic as well as therapeutic implications. Thus, the presence of symptom-free coronary heart disease, angiographically verified after the finding of a pathological exercise electrocardiogram, ${ }^{6}$ has recently been shown to carry a grave prognosis. ${ }^{13}$ On the other hand, normal coronary angiograms in similar patients have been reported to indicate a favourable prognosis. ${ }^{14} 15$

One side effect of cardiovascular surveys, and in particular surveys that include electrocardiographic exercise testing, is the identification of a large number of subjects with pathological exercise electrocardiograms and/or mild or atypical angina. ${ }^{615}$ Radionuclide techniques should be a valuable tool for further diagnostic evaluations in such cases. If the ${ }^{201} \mathrm{Tl}$ studies only had been applied, however, one could easily have reached the conclusion that nothing was wrong with the men from group 2 , for example. The ${ }^{99 \mathrm{~m}} \mathrm{Tc}$ studies of left ventricular function, however, disclosed significant abnormalities in a high number of subjects from group 2 as well as from group 3. As presented above, several subjects showed less than a $5 \%$ increase in left ventricular ejection fraction (or even a decrease) during exercise. An increase in left ventricular ejection fraction of less than $5 \%$ has been said to indicate a pathological response, 51112 a view which is similar to ours among the 25 normal subjects. The subnormal response in subjects from group 2, and also to a lesser extent for patients from group 3, cannot be explained as a physiological ageing phenomenon since we did not find any association between age and left ventricular ejection fraction response. ${ }^{16}$ Our findings of impaired myocardial function in subjects from groups 2 and 3 are in agreement with other recent reports. ${ }^{17} 18$

As mentioned above, two men from the original group of 36 men had died suddenly, and in addition three had developed congestive heart failure. In four men from group 2 nonspecific pathological myocardial changes were found in endomyocardial biopsies together with raised end-diastolic pressures, that is findings consistent with a diagnosis of cardiomyopathy. ${ }^{78}$ In the light of these combined findings it is conceivable that the ST depression in the exercise electrocardiograms as well as the subnormal increase in left ventricular ejection fraction during exercise reflect signs of cardiomyopathy in an early phase in several cases.

The demonstration of coronary artery spasms as a probable cause of coronary artery narrowing associated with angina pectoris has challenged the traditional view that only fixed coronary artery stenoses may cause a reduction in blood flow sufficient to cause transient myocardial ischaemia. ${ }^{1920}$ In the present study reversible myocardial ischaemia related to possible coronary artery spasm was rare, since it was only suggested in two patients from group 3 and none from group 2. This is in agreement with some and in conflict with other reports of similar groups of patients. ${ }^{182122}$ The differences may be explained by differences in patient selection and also by the fact that we did not use drugs that could provoke coronary artery spasm. ${ }^{23}$

In conclusion, the application of radionuclide techniques in subjects with asymptomatic ST depression on exercise electrocardiogram and in patients with angina pectoris can help in identifying patients who probably have coronary heart disease or other heart diseases. Patients with pathological radionuclide findings should be followed closely and receive appropriate treatment. On the other hand, subjects with normal radionuclide findings should be considered healthy and be reassured of a good prognosis.

\section{References}

1 Corne RA, Gotsman MS, Weiss A, et al. Thallium-201 scintigraphy in diagnosis of coronary stenosis. $\mathrm{Br} \mathrm{Heart} \mathcal{F}$ 1979; 41: 575-83.

2 Berger HJ, Zaret BL. Nuclear cardiology (I). $N$ Engl f Med 1981; 305: 797-807.

3 Slutsky R, Karliner J, Ricci D, et al. Response of left ventricular volume to exercise in man assessed by radionuclide equilibrium angiography. Circulation 1979; 60: $565-71$.

4 Iskandrian AS, Segal BL. Value of exercise Thallium201 imaging in patients with diagnostic and nondiagnostic exercise electrocardiograms. Am 7 Cardiol 1981; 48: 233-8.

5 Berger HJ, Zaret BL. Nuclear cardiology (II). $N$ Engl F Med 1981; 305: 855-65.

6 Erikssen J, Enge I, Forfang K, Storstein O. False positive diagnostic tests and coronary angiographic findings in 105 presumably healthy males. Circulation 1976; 54: $371-6$.

7 Baandrup U, Florio RA, Rehahn M, Richardson PJ, Olsen EGJ. Critical analysis of endomyocardial biopsies from patients suspected of having cardiomyopathy. II Comparison of histology and clinical/haemodynamic information. Br Heart f 1981; 45: 487-93. 
8 Opherk D, Zebe H, Weibe E, et al. Reduced coronary reserve and ultrastructural changes of the myocardium in patients with angina pectoris but normal coronary arteries. Circulation 1979; 60: abstract 288. (Also published in $Z$ Kardol in German.)

9 Richardson PJ, Livesley B, Oram S, Olsen EGJ, Armstrong $\mathrm{P}$. Angina pectoris with normal coronary arteries. Transvenous myocardial biopsies in diagnosis. Lancet 1974; ii: 677-80.

10 Judkins MP. Percutaneous transfemoral selective coronary arteriography. Radiol Clin North Am 1968; 6: 46792.

11 Jones RH, McEwan P, Newman GE, et al. Accuracy of diagnosis of coronary artery disease by radionuclide measurement of left ventricular function during rest and exercise. Circulation 1981; 64: 586-601.

12 Iskandrian AS, Hakki AH, Kane SA, Segal BL. Quantitative radionuclide angiography in assessment of hemodynamic changes during upright exercise. Observations in normal subjects, patients with coronary artery disease and patients with aortic regurgitation. Am $\mathcal{J}$ Cardiol 1981; 48: 239-46.

13 Erikssen J, Mundal R. The non-infarct patient with coronary artery disease: can a high risk group be identified? Ann NY Acad Sci 1982; 382: 438-49.

14 Isner JM, Salem DN, Banas JS Jr, Levine HJ. Long term clinical course of patients with normal coronary arteriography: follow-up study of 121 patients with normal and nearly normal coronary arteriograms. Am Heart f 1981; 102: 645-53.

15 Betriu A, Pare JC, Sanz GA, et al. Myocardial infarction with normal coronary arteries: a prospective clinicalangiographic study. Am $\mathcal{F}$ Cardiol 1981; 48: 28-32.
16 Weisfeldt LM. Ageing of the cardiovascular system. $N$ Engl f Med 1980; 303: 1172-4.

17 Berger HJ, Sands MJ, Davies RA, et al. Exercise left ventricular performance in patients with chest pain, ischemic appearing exercise electrocardiograms, and angiographically normal coronary arteries. Ann Intern Med 1981; 94: 186-91.

18 Murray RG, McKillop JH, Bessent RG, et al. Evaluation of thallium-201 scintigraphy in coronary artery disease. Br Heart f 1979; 41: 568-74.

19 Oliva PB, Breckinridge JC. Arteriographic evidence of arterial spasm in acute myocardial infarction. Circulation 1977; 56: 366-74.

20 Maseri A, L'Abbate A, Baroldi G, et al. Coronary vasospasm as a possible cause of myocardial infarction. $N$ Engl f Med 1978; 299: 1271-7.

21 Dunn RF, Wolff L, Wagner S, Botvinick EH. The inconsistent pattern of thallium defects: a clue to the false positive perfusion scintigram. Am $\mathcal{F}$ Cardiol 1981; 48: 224-32.

22 Gibbons RJ, Lee KJ, Cobb F, Jones RH. Ejection fraction response to exercise in patients with chest pain and normal coronary arteriograms. Circulation 1981; 64: 952-7.

23 Specchia G, de Servi S, Falcone C, et al. Significance of exercise-induced ST-segment elevation in patients without myocardial infarction. Circulation 1981; 63: 46-53.

Requests for reprints to Dr Erik Thaulow, Laboratory of Cardiology, Medical Department B, Rikshospitalet, Oslo 1, Norway. 